\title{
Diagnosis of Head Lice Infestations: An Evidence-Based Review
}

\author{
Hermann Feldmeier*
}

Institute for Microbiology and Hygiene, Charité University Medicine, Campus Benjamin Franklin, Hindenburgdamm 27, D-12203 Berlin, Germany

\begin{abstract}
The diagnosis of head lice infestation is made through visual inspection of the hair and the scalp or by dry/wet combing. The choice of the method essentially depends whether the examiner aims at the detection of active infestation presence of trophic stages and/or viable eggs - or wants to identify a historical infestation (presence only of nits/dead eggs). For the latter purpose, visual inspection of the hair at five predilection sites (temples, behind the ears, neck) is the method of choice (sensitivity $80 \%-90 \%$ ). The optimal method for the diagnosis of active head lice infestation is wet combing with a sensitivity $\geq 90 \%$, even in children with a low infestation intensity. In resource-pour settings, where pediculosis capitis is very common and infestation intensity is high, self-diagnosis by affected individuals or their caretakers is an accurate alternative.
\end{abstract}

Keywords: Head lice infestation, diagnosis, sensitivity, specificity, prevalence.

\section{INTRODUCTION}

Head lice infestation is one of the most common parasitic infections in childhood. Despite the importance attributed to the condition by caregivers, governesses and teachers, it is still a matter of debate how to diagnose this parasitic skin disease. Accurate diagnosis, though, is the prerequisite for effective elimination of the infestation, irrespective of whether the purpose is the identification of individual cases, such as in clinical practice, or the interruption of transmission in an endemic situation e.g. in a kindergarten [1].

The most commonly used diagnostic technique is visual inspection of the hair and the scalp. This method is easy, rapid and does require only minimal resources. Alternatively, one can use a detection comb, either directly on dry hair or after the hair has been moistened with a conditioner. In the latter case the hair is systematically combed from the scalp to the tips. This method is more timeconsuming, requires trained personnel and is resourceintensive [2]. Diagnostic combing has the advantage that it is an effective therapeutic means by itself, whereas visual inspection is not.

Only active pediculosis capitis - defined as the presence of nymphs, adults and/or viable ova - requires treatment. Presence of empty egg shells (nits) or apparently dead ova is no indication for treatment. In clinical praxis, though, it is not easy to differentiate between an active and an infestation experienced in the recent past. At least in industrialized countries, the number of head lice present on the head of an individual is usually rather low ( $\leq 10$ trophic stages in most cases) [3], and a few parasites are easily overlooked. It is also rarely appreciated that diagnosis of head lice infestation needs some skills and a certain degree of devotion.

*Address correspondence to this author at the Institute for Microbiology and Hygiene, Charité University Medicine, Campus Benjamin Franklin, Hindenburgdamm 27, D-12203 Berlin, Germany; Tel: +49 4181 281628; Fax:+49 4181 36943; E-mail: hermann.feldmeier@charite.de

\section{DIAGNOSIS BASED ON THE PRESENCE OF EGGS}

The presence of eggs attached to the hair - in the absence of living mobile stages - is not considered adequate evidence for active pediculosis and therefore is not sufficient to prescribe a pediculocide $[1,3]$. In fact, there are several lines of evidence arguing against the assumption that the presence of eggs is a valid indicator of active infestation. First, the differentiation between viable eggs, dead embryos retained in egg shells and empty nits is difficult even for experienced investigators and impossible for laymen and normal doctors $[4,5]$. Second, measuring the distance between an egg and the scalp as a proxy of the viability of the egg - hence, the odds that a nymph will hatch - is unreliable [6]. Third, only a portion of individuals with eggs attached to their hair, but without trophic stages, convert to carriers of trophic stages. In a study in Turkey, Balcioglu et al. [5] found that of 138 students with eggs attached to their hair during a survey, only $7 \%$ showed nymphs or adults two weeks later.

Taking into account these facts, there are only a few situations in which the identification of individuals carrying eggs/nits is meaningful. For instance, if the determination of period prevalence in a population is the goal, the number of individuals with eggs/nits together with the distance between eggs and scalp will reflect the number of individuals having carried adult lice during a defined period of time. The presence of eggs/nits will also help to track transmission in small outbreaks.

\section{DIAGNOSIS OF HISTORICAL INFESTATION}

The optimal method to diagnose historical infestation is by visual inspection of the hair. To do so, the hair is systematically screened with the aid of an applicator stick. Usually, the inspection is confined to five predilection sites: temples left and right, behind the ears, and the neck. For reasons unknown, lice prefer to cement their eggs to hair shafts in these topographic areas [7].

A systematic, observer-blinded study in school-children has shown that the sensitivity of visual inspection in 
detecting historical infestation was $86 \%$ ( $95 \%$ confidence intervals $82-90 \%$ ), whereas sensitivity of wet combing was $68 \%$ (95\% CI 63-74\%) [8]. However, this study also showed that - if only a few eggs/nits are present - these are overlooked by visual inspection, but confirmed by wet combing. Hence, the accuracy of both methods is rather similar (96\% vs 92\%) [8].

\section{DIAGNOSIS OF ACTIVE INFESTATION}

Due to its simplicity, visual inspection is also frequently used for the diagnosis of active infestation. In this case adult parasites or nymphs are looked for on the scalp. After parting the hair with an applicator stick, the scalp is examined systematically. Since nymphs are at the limit of visibility, an (illuminated) magnifying glass is recommended.

Unfortunately, the sensitivity of visual inspection is unacceptably low, even when the whole scalp is inspected $[5,8,9]$. In one study, in only $6 \%$ of children screened for head lice, nymphs or adults were found on the scalp by visual inspection, as compared to $25 \%$ after combing, resulting in a sensitivity of visual inspection of $22 \%$ [10]. More recent data from Turkey and Germany revealed a similar low sensitivity of $31 \%$ and $29 \%$, respectively, as compared to wet combing $[5,8]$. Hence, in settings where children have only a few trophic stages on their scalp, visual inspection cannot be recommended as a diagnostic means to diagnose active infestation.

The situation is different in resource-poor communities, particularly in the developing world, where infestation intensity is usually high and mothers are daily confronted with head lice infestation. In this context visual inspection may be an alternative means to diagnose active infestation. This is nicely illustrated by a study including mothers living in a slum in Brazil, who screened the heads of their children regularly. When these women used visual inspection, the sensitivity of the method was $43 \%$ [11]. In a populationbased study in another endemic community the sensitivity of visual inspection performed by mothers of affected children was $35 \%$ [12].

An even more simple approach to diagnose active head lice infestation is asking affected individuals about their supposed infestation status. This approach has been used in resource-poor areas where people commonly have head lice, but no adequate access to health care. Studies in Brazil and Nigeria have shown that under these circumstances caretakers, when being asked about the presence of head lice on the head of their children, diagnosed the infestation status with a sensitivity of $74 \%-81 \%[12,13]$. In the case of severe infestation, the sensitivity of self-diagnosis was as high as $92 \%$ [13].

The most reliable method to diagnose active head lice infestation is by detection combing. Detection combing can be performed on dry or wet hair. Combs must have parallelsided teeth and a distance of $\leq 0.3 \mathrm{~mm}$ between the teeth, so that even the small first instar nymphs are caught between the teeth. Although more time-consuming and more expensive, wet combing is preferable to dry combing, since hair wetted with a conditioner is easier to disentangle and afterwards to comb out systematically - which makes it more difficult for head lice to "escape". If a conditioner is applied onto the hair first, lice enter into stasis, do not crawl away and therefore stick to the comb and are detected in the conditioner liquid. After each strike, the conditioner is wiped on sanitary paper to detect lice stuck between the teeth of the comb.

If wet combing is done systematically from one side of the head to the other, the sensitivity of the method in children with a low infestation intensity is in the order of $90 \%$ (95\% confidence limits $87-94 \%$ ) [8]. The negative predictive value of this method is $99 \%$ [8].

If wet combing is performed for a diagnostic purpose only, it is stopped, when the first nymph/lice is detected. If one wants to take the therapeutic effect of wet combing as an advantage, the hair has to be combed completely. A disadvantage of wet combing is that this method is more resource-intensive (need of conditioner, towels, sanitary paper and hairdryer).

\section{SPECIFICITY OF DIAGNOSTIC METHODS}

As adult head lice can be identified with the naked eye, and eggs/nits can be easily differentiated from artefacts, in theory the specificity of visual inspection and of detection combing should be very high. However, the methods are frequently applied by people who are not acquainted with the morphological characteristics of head lice and their eggs and consequently misinterpret what they see. In the USA, for instance, only $59 \%$ of 614 samples sent to a reference centre for diagnosis of head lice infestation contained trophic forms or eggs [4]. Debris such as dandruff and other epidermal material was found in $35 \%$ of all samples, and other arthropods (book lice, beetles, mites, bed bugs etc.) in 5\%. In addition, only $53 \%$ of the specimens thought to contain a trophic stage or a viable egg actually showed the corresponding life stage of the parasite. The remaining samples contained mostly nits, indicating an infestation in the past. This is a matter of concern, since potentially hazardous pediculocides were applied to $62 \%$ of individuals with specimens without any lice material [4].

\section{PREVALENCE}

The low sensitivity of visual inspection for the diagnosis of active infestation leads to false-low estimations of prevalence in surveys. Mumcuoglu et al. [10] found a 4-fold higher prevalence of active infestation after dry combing, as compared to visual inspection in children with a high intensity of infestation. Similarly, in schoolchildren Balcioglu et al. [5] determined a 3-fold higher prevalence after dry combing as compared to visual inspection. In a study in German school children, the use of visual inspection underestimated the true prevalence of active infestation by a factor 3.5 [8].

\section{CONCLUDING REMARKS}

It is frequently overlooked that in parasitic diseases the sensitivity of diagnostic methods depends on the intensity of infestation [14]. In contrast to settings in the developing world where a high intensity of infestation is the rule, in industrialized countries most children carry only a few lice $[1,15,16]$. By consequence, the optimal detection method for the diagnosis of active infestation should identify even a single louse and should have a high negative predictive value 
to exclude that individuals classified as negative are actually false-negative with the potential to spread the parasite.

\section{REFERENCES}

[1] Burgess IF. Human Lice and their control. Annu Rev Entomol 2004; 49: 457-81.

[2] De Maeseneer J, Blokland I, Willems S, Vander Stichele R, Meersschaut F. Wet combing vs traditional scalp inspection to detect head lice in schoolchildren: observational study. BMJ 2000; 321: 1187-8.

[3] Feldmeier H. Pediculosis capitis: Die wichtigste Parasitose des Kindesalters. Kinder- und Jugendmedizin 2006; 6: 249-59.

[4] Pollack RJ, Kiszewski AE, Spielman A. Overdiagnosis and consequent mismanagement of head louse infestations in North America. Pediatr Infect Dis J 2000; 19: 689-93.

[5] Balcioglu C, Burgess IF, Limoncu ME, et al. Plastic detection comb better than visual screening for diagnosis of head louse infestation. Epidemiol Infect 2008: 1-7.

[6] Williams LK, Reichert A, MacKenzie WR, Hightower AW, Blake PA. Lice, nits, and school policy. Pediatrics 2001; 107: 1011-5.

[7] Nash B. Treating head lice. BMJ 2003; 326: 1256-1257.

[8] Jahnke C, Bauer E, Hengge UR, Feldmeier H. Accuracy of diagnosis of pediculosis capitis: visual inspection vs wet combing. Arch Dermatol 2009; 145: 309-13.
[9] Burgess IF. Human lice and their management. Adv Parasitol 1995; 36: $271-342$

[10] Mumcuoglu KY, Friger M, Ioffe-Uspensky I, Ben Ishai F, Miller J. Louse comb $v s$ direct visual examination for the diagnosis of head louse infestations. Pediatr Dermatol 2001; 18: 9-12.

[11] Heukelbach J, Kuenzer M, Counahan M, Feldmeier H, Speare R. Correct diagnosis of current head lice infestation made by affected individuals from a hyperendemic area. Int J Dermatol 2006; 45: 1437-8.

[12] Pilger D, Khakban A, Heukelbach J, Feldmeier H. Self-diagnosis of active head lice infestation by individuals from an impoverished community: high sensitivity and specificity. Rev Inst Med Trop São Paulo 2008; 50: 121-2.

[13] Ugbomoiko US, Speare R, Heukelbach J. Self-diagnosis of head lice infestation in rural Nigeria as a reliable rapid assessment tool for pediculosis. Open Dermatol J 2008; 2: 95-7.

[14] Feldmeier H. In: Jordan P, Webbe G, Sturrock RF, Eds. Human Schistosomiasis. Wallingford, CAB International 1993; pp. 271-94.

[15] Heukelbach J, Wilcke T, Winter B, Feldmeier H. Epidemiology and morbidity of scabies and pediculosis capitis in resource-poor communities in Brazil. Br J Dermatol 2007; 153: 150-6.

[16] Speare R, Thomas G, Cahill C. Head lice are not found on floors in primary school classrooms. Aust N Z J Public Health 2002; 26: 208-11.

This is an open access article licensed under the terms of the Creative Commons Attribution Non-Commercial License (http://creativecommons.org/licenses/by-nc/ 3.0/) which permits unrestricted, non-commercial use, distribution and reproduction in any medium, provided the work is properly cited. 